\title{
Overview On Optimization Methods of Rectangular Dielectric Resonator Antenna
}

\author{
V. Lakshmi Parvathi*1 ${ }^{*}$ Rajesh. B. Raut ${ }^{2}$ and Biswajeet Mukherjee ${ }^{3}$ \\ ${ }^{1}$ Research Scholar, Shri Ramdeobaba College of Engineering and Management, Nagpur, India \\ ${ }^{2}$ Shri Ramdeobaba College of Engineering and Management, Nagpur, India \\ ${ }^{3}$ PDPM, Indian Institute of Information Technology, Design and Manufacturing, Jabalpur, India
}

\section{ABSTRACT}

This paper presents a brief review on the Rectangular Dielectric Resonator Antennas (RDRAs) for Sub-6 GHz band of frequencies. Various resonant modes, feeding mechanisms, bandwidth and gain enhancement techniques and size reduction methods have been discussed. Comparisons and advantages of dielectric resonator antenna over microstrip patch antenna have also been presented.

\section{KEY WORDS: RDRA, CIRCULAR POLARIZATION, RESONANT MODES, BANDWIDTH, GAIN.}

\section{INTRODUCTION}

Modern wireless communication systems require suitable antennas to operate at higher frequencies such as microwave and millimetre wave frequencies. Traditional microstrip patch antennas are not suitable for these frequencies due to considerable conductor losses at those frequencies. Dielectric Resonator Antenna is a microwave antenna consists of a ceramic block of materials with higher permittivity values which work efficiently at these frequencies. When the dielectric resonator is not enclosed by a metal cavity and with proper excitation, it radiates efficiently and thus becomes a radiator. After vast research, in 1939, R.D. Richtmeyer theoretically demonstrated that non-metalized objects can resonate and function as an antenna, and these are named as Dielectric Resonator Antenna [Petosa et.al.,], [R. S. Yaduvanshi et.al.,]. In 1980s, Long, McAllister

\section{ARTICLE INFORMATION}

${ }^{*}$ Corresponding Author: parvathivl@rknec.edu

Received 18th Oct 2020 Accepted after revision 23rd Dec 2020

Print ISSN: 0974-6455 Online ISSN: 2321-4007 CODEN: BBRCBA

Thomson Reuters ISI Web of Science Clarivate Analytics USA and Crossref Indexed Journal

\section{1) Clarivate $\begin{gathered}\text { Analytics } \\ \text { rossef }\end{gathered}$}

NAAS Journal Score 2020 (4.31)

A Society of Science and Nature Publication,

Bhopal India 2020. All rights reserved.

Online Contents Available at: http//www.bbrc.in/

Doi: $h t t p: / / d x$.doi.org/10.21786/bbrc/13.14/113 and Shen started the study of dielectric resonators as an antenna element with an analysis of characteristics of hemispherical, Cylindrical, and Rectangular shapes along with its material properties. DRA offers advantages like high impedance bandwidth, high gain, and most importantly freedom from metallic losses [Biswajeet et.al.,]. The fields of the mode must not be strongly restricted within the resonator and hence, it can be easily fed to generate efficient radiation [K. W. Leung et.al.,].

2. Rectangular Dielectric Resonators: The dielectric resonators have numerous advantages than microstrip patch antenna. In microstrip antenna radiation occurs due to the narrow slots only whereas in dielectric resonator the radiation is due to the whole surface except the grounded part. The limitations of patch antenna such as low gain, narrow bandwidth and narrow beam characteristics can be eliminated with rectangular dielectric resonator antenna by operating in higher modes and hybrid modes and most importantly DRAs don't suffer from surface waves [Petosa et.al.,]. Dielectric resonator antenna with a rectangular cross-section having length $\mathrm{w}$, width $\mathrm{d}$, and height $\mathrm{h}$ as shown in fig (1) offers greater design flexibility to achieve desired profile and radiation characteristics for a selected dielectric constant and resonance frequency by choosing different aspect ratios such as length/width and length/height independently [Petosa et.al.,], [R. K. Mongia et.al.,].

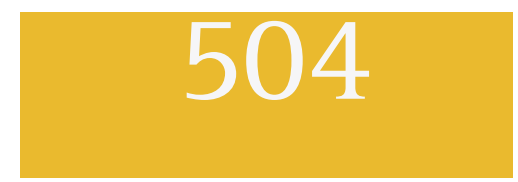


Figure 1: Isolated rectangular dielectric resonator antenna [R. K. Mongia et.al.,]

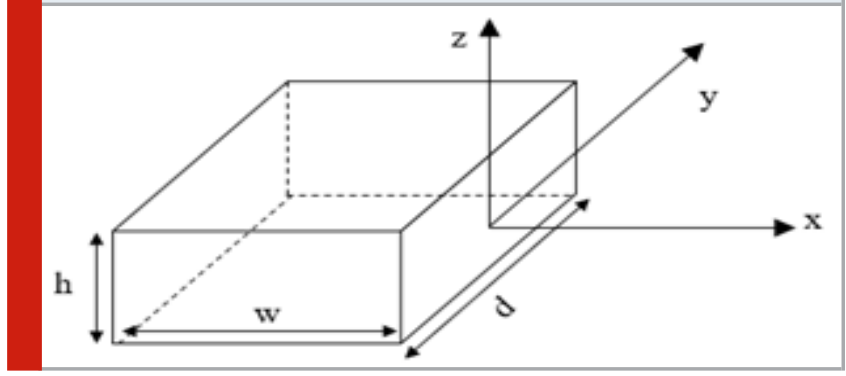

One more feature with rectangular shape compared with other structures is that the mode degeneracy can be overcome with proper selection of aspect ratios, thus limiting the excitation of undesirable modes and can lower cross polarization levels. As per the literature review, mainly two approximations are available to analyse the rectangular dielectric antennas, namely;

(i)- Magnetic wall model by Okaya and Barash [Okaya. A \& Barash]

(ii)- Dielectric waveguide model

The DWM method utilizes both Marcatili's approximation and EDC approximation for the characteristic analysis of rectangular dielectric resonator.

Resonant modes: RDRA with a 3-dimensional structure supports various modes for numerous applications. Resonant modes represent the radiating phenomena of $\mathrm{E}$ and $\mathrm{H}$ field patterns to predict the radiation characteristics of the antenna [K. W. Leung et.al.,]. Okaya and Barash [Okaya. A \& Barash] described the resonance modes of an isolated rectangular DRA into two categories, namely, TE and TM modes. But the existence of TM modes in rectangular resonator was not proved experimentally [K. W. Leung et.al.,], [R. K. Mongia et.al.,]. Van Bladel classified the modes as confined and nonconfined types and these modes satisfy the below conditions at the surface of the resonator:

$$
\vec{E} \cdot \hat{n}=0
$$

$\hat{n} \times \vec{H}=0$

The modes which satisfy both equations (1) and (2) are known as confined modes, while those which satisfy equation (1) are called nonconfined modes [Biswajeet et.al.,]. Van Bladel also stated that the dielectric objects like cylindrical and spherical shapes with the body of revolution only can support the confined modes. Since rectangular DRA is not a body of revolution, it supports nonconfined modes only. In general, the DRA in rectangular shape has a greater number of modes compared to its cylindrical and hemispherical shapes and this feature helps to improve the impedance bandwidth when adjacent modes have the same radiation phenomenon. One common approach to predict the modes in rectangular DRA is the direct waveguide model (DWM) method. By using this method, the E and H-field propagation ofTE ${ }^{\mathrm{x}}$ mode of RDRA is approximated [R. S. Yaduvanshi], [Biswajeet et.al.,] as given below:

The transcendental equation is as follows:

$$
k_{x} \tan \left(\frac{k_{x} d}{2}\right)=\sqrt{\left(\varepsilon_{r}-1\right) k_{0}^{2}-k_{x}^{2}}
$$

Where

$$
k_{x}^{2}+k_{y}^{2}+k_{z}^{2}=\varepsilon_{r} k_{o}^{2}, k_{0}=\frac{2 \pi f_{0}}{c}, k_{y}=\frac{\pi}{w} \text { and } k_{z}=\frac{\pi}{2 h}
$$

Where $\mathrm{k}_{\mathrm{x}}, \mathrm{k}_{\mathrm{y}}, \mathrm{k}_{\mathrm{z}}$ and $\mathrm{k}_{0}$ are wavenumbers in $\mathrm{x}, \mathrm{y}, \mathrm{z}$-axes and free space, respectively. $\mathrm{w}, \mathrm{d}$ and $\mathrm{h}$ are length, width and height of the RDRA, respectively.

2.2 Feeding mechanisms: The type of feeding technique and its location plays a major role in determining which modes are excited and how much power is coupled between the port and the antenna. This, in turn, will determine the input impedance, resonance frequency, Q-factor and radiation characteristics of RDRA.

The RDRAs can be excited by various techniques as stated below:

2.2.1 Aperture Coupling: This type of feeding network offers the advantage of low spurious radiation from the feed line by providing isolation between the aperture and feed network, consequently increasing the polarization purity of the RDRA. The amount of coupled power and strength of the magnetic field at the slot position can be affected by the slot position. An increase in the slot length can increase the coupled power but decreases the resonance frequency. This feeding technique provides a relatively narrow bandwidth. Aperture coupling may not be suitable for lower frequencies due to the realization of the large size of the slot.

2.2.2 Probe Coupling: In this coupling, the probe can be placed either inside the RDRA or adjacent to the RDRA. The advantage of the probe inside the RDRA is that high coupling can be achieved results in high radiation efficiency. The drawback of this structure is that a hole needs to be drilled inside the RDRA and the hole dimensions need to be matched with probe length and width otherwise the dielectric constant of RDRA will get effected causing the resonance frequency shift. Probe adjacent to the RDRA results with weaker coupling to RDRA.

2.2.3 Microstrip Line Coupling: By using microstrip coupling we can excite the TE $\delta 11$ mode of the rectangular DRA. Stripline determines the coupling strength and mode of excitation. Strong coupling can be achieved by choosing strip length slightly shorter than one quarter wavelength of the resonance frequency. Microstrip line can be etched on the same substrate to provide planar structure but introduces an undesired air gap between rectangular DR and substrate. 
2.2.4 Coplanar-Waveguide Coupling: With this coupling, good efficiency of the antenna can be achieved by resonator antenna from substate. Coupling can be enhanced by altering the shape of the coupling slot. This technique is best suitable for antennas operating at millimetre wave frequencies.

2.3 Circular Polarization in RDRAs: Circular polarization is often used to overcome the polarization rotation effects due to atmospheric effects such as multipath fading and reflections from the obstacles. The circularly polarized antennas are independent to transmitter and receiver positioning. Circular polarization can be generated by following single point feed, dual point feed and sequential rotation methods. Various circularly polarized antennas are proposed for satellite, radar and wireless communications [Jamaluddin. M. H et.al., \& R. K. Gangwar et.al.,].

A rectangular dielectric resonator antenna fed by $\mathrm{H}$-shaped conformal metal strips is designed for satellite and WiMAX applications [Jamaluddin. M. H et.al.,]. Due to metal strips, a pair of degenerate modes $T E_{\delta_{13}^{*}}^{x}$ and $T E_{1,83}^{y}$ are excited achieving a broad CP impedance bandwidth of $20 \%$ along with wide beamwidth and with a peak gain of $6.8 \mathrm{dBi}$. Circular polarization using single point fed can be achieved by following various techniques like modifications in the basic DRA shapes, loading a monopole antenna into the resonator structure or by using different feed shapes. Authors in [R. K. Gangwar et.al.,] reported a rectangular dielectric resonator antenna fed with flag shaped microstrip line. By creating notches in the feedline excites $T E_{111}^{x}$ and $T E_{11}^{y}$ orthogonal modes to generate circular polarization.

Figure 2: Structural representation of the proposed circularly polarized rectangular DRA [R. K. Gangwar et.al.,]

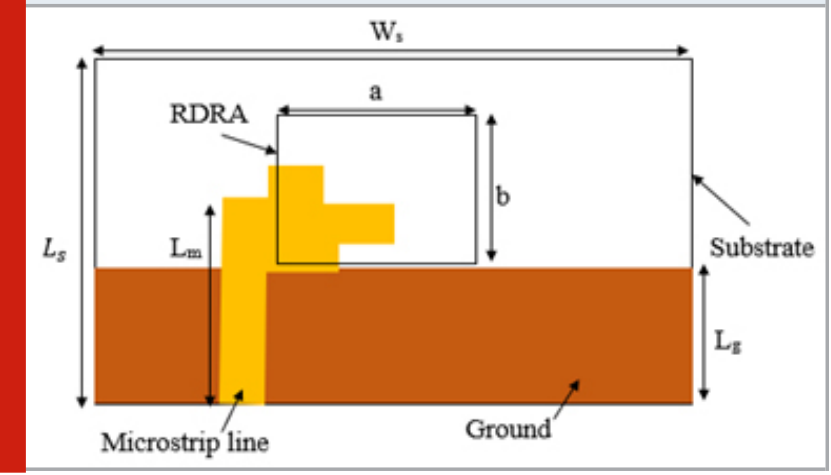

The impedance bandwidth achieved is $58.36 \%$ along with $3 \mathrm{~dB}$ axial ratio bandwidth of $47.27 \%$ at $2.5 \mathrm{GHz}$ shown in fig (2). Researchers proposed a stacked rectangular dielectric resonator antenna for dual band operation [Zou. M \& Pan. J]. The resonator is fed with cross slot of unequal arm lengths so as to achieve the wideband circular polarization. If the cross slot with an arm length of half guided wavelength is chosen, resonance modes will divide into two degenerate resonance modes with equal amplitude and opposite phase angles. With this mechanism, the structure shown in fig (3) achieved a lower band AR bandwidth of 9.7\% and upper band AR bandwidth of $20 \%$.

A notched rectangular dielectric resonator is proposed fed with stair shaped slot to obtain wide axial ratio bandwidth [Pandey. V. S et.al.,]. Furthermore, two notches are introduced diagonally on the sides of the DRA to enhance the CP bandwidth. The top notched corner is coated with conductive metal layer. This layer acts as parasitic element and adjacent 3-dB bands are merged for further enhancement in axial ratio bandwidth. The impedance bandwidth and AR bandwidth of $66.45 \%$ and $55.22 \%$ are obtained at resonance frequency of $4.75 \mathrm{GHz}$ with a gain of $2 \mathrm{dBi}$.

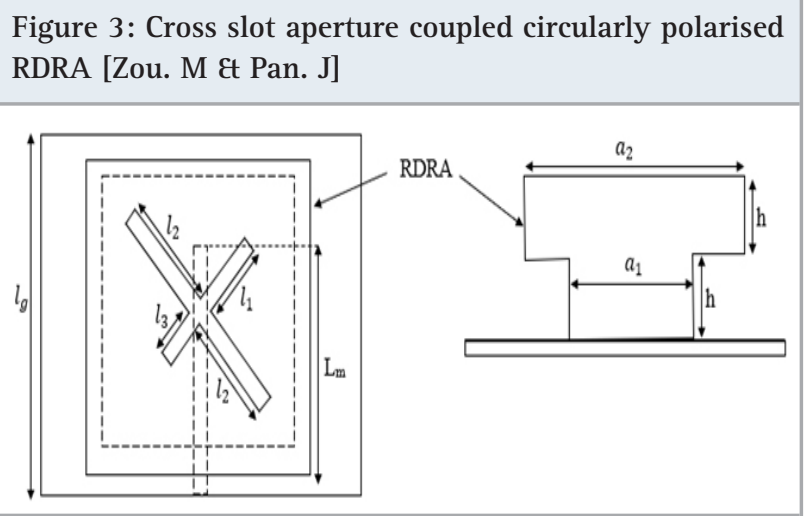

Parameters enhancement: In this section, techniques for enhancement of parameters such as Bandwidth and Gain have been discussed.

3.1 Bandwidth enhancement techniques: Numerous technologies have been evolved to enhance the bandwidth to fulfill the requirements of the large impedance bandwidth, high data rates etc., As the bandwidth of the resonator antenna is inversely proportional to dielectric constant, by choosing the dielectric material with high dielectric constant (Er) value we can increase the impedance bandwidth of the DRA. By introducing an air gap between the ground plane and the resonator, the surface area/volume ratio gets reduced and impedance bandwidth is enlarged from 50.3\% to $81 \%$ in [A. K. Roy Et Sukla Basu]. The air gap is discussed in [L. E. Davis et.al.,] with improved bandwidth by lowering unloaded Q-factor.

One approach to enhance the bandwidth is by stacking two or more layers with different dielectric constants and is discussed in [Krishsagar. P et.al., \& Gebril. K. K]. In [Krishsagar. P et.al.,], two different dielectric materials having different resonance frequency are kept side by side to attain the operational bandwidth of $131 \%$. The defected ground structure is used with a rectangular cut in the middle of the ground at an angle of 450 as shown in fig 4. In [Gebril. K. K], [Abedian. M et.al.,], stacked configurations are proposed with high aspect ratios in order to shift the frequency of higher order mode 
towards the dominant mode to make a vast change in the bandwidth of the antenna.

Figure 4: Two segment UWB rectangular DRA [Krishsagar. P et.al.,]

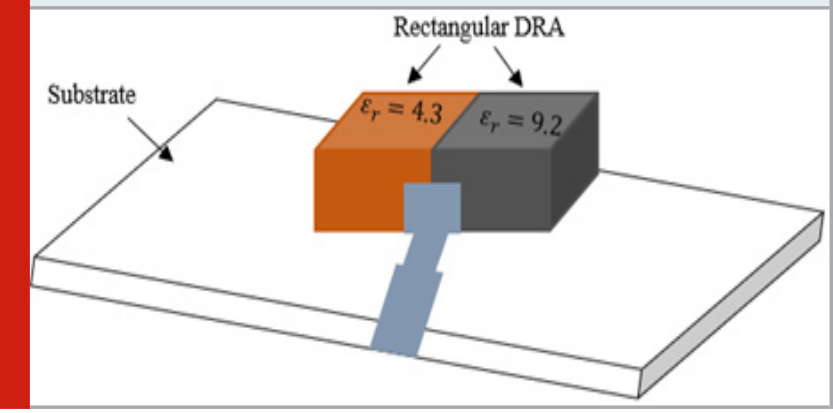

Another idea to improve the bandwidth is by using perforations. The perforation technique alters the effective permittivity of the dielectric material depending on the hole radius and spacing between the holes. In [Patel. P et.al.,], the circular polarization is achieved with four square shaped slots etching at diagonals of RDRA and in [Patel. P et.al.,] another perforated configuration based on edge grounding is proposed. The resonator is chopped to half of its volume by placing a metal plate at the edge. With this topology, 56\% impedance bandwidth at $2.4 \mathrm{GHz}$ is achieved along with considerable weight reduction. In [Petosa. A et.al.,], the perforated topology is designed for array applications using a single dielectric sheet. This structure eliminated the discontinuities between the resonators and provides ease of fabrication.

Hybrid RDRAs is one of the suitable methods for bandwidth enhancement. For hybrid topology either the feed network also acts as a radiator or another structure is used as a radiator. In [Yuan Gao et.al.,], a rectangular resonator is designed with centre fed CPW inductive slot which can work like a radiator and feed network simultaneously as shown in fig 5. By tuning the inductive slot length and DRA height, resonances of two radiators are merged and hence achieved an impedance bandwidth of $28.9 \%$ at $5 \mathrm{GHz}$ frequency.

Figure 5: Top view and Side view of the Wideband Hybrid RDRA [Yuan Gao et.al.,]

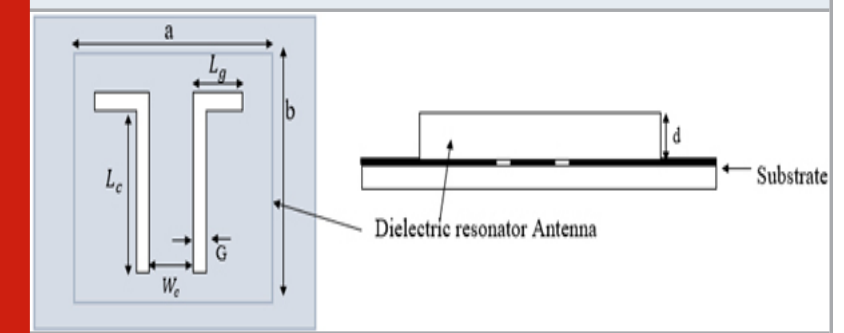

3.2 Gain enhancement techniques: A novel MTMloaded RDRA is designed [Killamsetty. V. K et.al.,] with metamaterial as a superstrate layout consisting of 50-unit cells of eight-shaped copper strips arranged in a $5 \times 10$ manner. The increment in gain is due to the lensing property of the MTM cells in the far field region and achieved a peak gain of $14 \mathrm{dBi}$ and impedance bandwidth of approximately $16 \%$ at $7.8 \mathrm{GHz}$ with low cross polarization levels. This antenna is a good candidate for radar systems, satellite communications.

A. Petosa et al., designed a simple rectangular DRA array prototype [Petosa \& Thirakoune] for high gain applications. In this array, each element is excited for different resonant modes by choosing different aspect ratios. High gain of up to $10.2 \mathrm{dBi}$ is achieved by exciting higher order modes. In the case of higher order modes, the rectangular DRA radiates with a more directive pattern and by properly selecting the aspect ratio, the radiation pattern can be controlled. In [Kishk. A. A et.al.,], a high gain RDRA arrays using parasitic elements is proposed in two configurations (i)-linear array of seven elements structure arranged as H-plane array and (ii)-five element cross shaped structure shown in fig 6 . For both cases, the parasitic elements are electromagnetically coupled with a driven element and the centre dipole is fed with aperture coupling. As a result, two beam shapes were obtained namely, vane beam and broadside radiation patterns. In broadside mode, the five-element structure achieved 10.1 $\mathrm{dB}$ gain and 610/410 E/H-plane beam width and in the case of seven-element structure, the gain and beamwidth are $11.14 \mathrm{~dB}$ and 1000/280 E/H-plane respectively.

Figure 6: Geometry of aperture coupled parasitic DRA arrays, (a) five element cross-shaped array (b) seven element linear array [Kishk. A. A et.al.,]

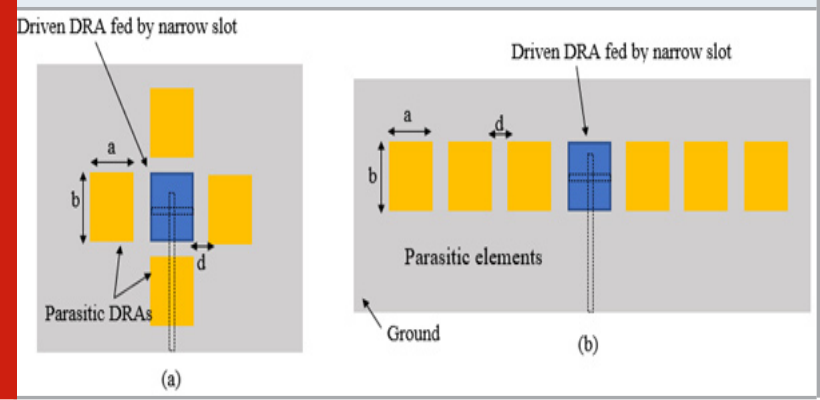

In [Fakhte. S et.al.,], grooves are introduced on the sidewalls of the rectangular dielectric resonator antenna to increase the boresight radiation patterns and to narrow the main beamwidth. By carefully adjusting the notch depths $(d x)$ the maximum peak gain achieved is 9.6 $\mathrm{dB}$ in the boresight direction and the increment in the gain is due to the electric field magnitude in the notch regions. Exciting the DRA into higher order modes increases the antenna gain to fulfil the requirement of the high frequency applications. At higher frequencies, the wave gets attenuated due to atmospheric conditions. Circularly polarized DRAs are more suitable at these situations and do not depend on transceiver positions. So, a two layered circularly polarised rectangular dielectric polarised antenna is designed to operate in higher order mode [Abdulmajid. A. A et.al.,]. In this structure, a high permittivity dielectric resonator is incorporated into a lower dielectric medium. The outer dielectric layer is responsible for bandwidth enhancement. The RDRA 
is excited to higher order mode TE11,11 by attaining maximum gain of $11 \mathrm{dBi}$ at $11.3 \mathrm{GHz}$.

Figure 7: Miniaturised CP RDRA (a) Top view (b) Front and back view (c) metal strips on resonator sides [Varshney. G et.al.,]

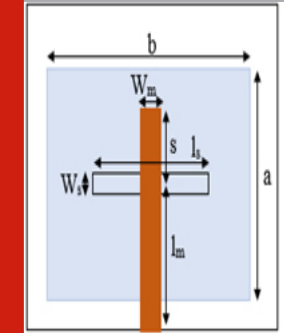

(a)

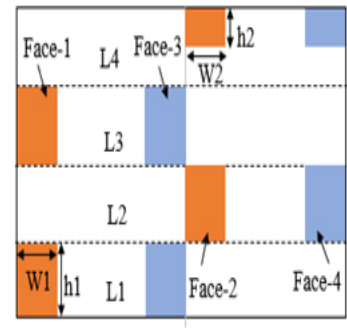

(b)

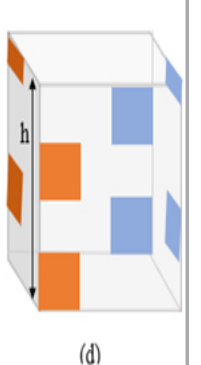

4. Miniaturization of RDRAs: Nowadays, low profile antennas are the major requirement in wireless communication. The antennas can be made compact by using various techniques such as the selection of high permittivity material, applying some modifications to the regular structures or by selecting high surface to volume ratio etc., In general, the size of the DRA and its dielectric constant have inverse relation $\left({ }_{2 \alpha \varepsilon^{-1 / 2}}\right)$. So, by selecting high dielectric constant material, the size of the DRA can be reduced. Along with size reduction, high dielectric constant has a negative impact on impedance bandwidth. So, there is a trade-off between size and bandwidth. In [Mongia. R. K et.al.,], aperture coupled RDRA with high dielectric constant $\left(_{\varepsilon r}=100\right)$ is proposed for low profile applications with approximately 3\% reasonable bandwidth.

Table 1. Radiation characteristics of the reference rectangular antennas

\begin{tabular}{|c|c|c|c|c|c|}
\hline $\begin{array}{l}\text { Reference } \\
\text { /Year }\end{array}$ & $\begin{array}{c}\text { Dielectric } \\
\text { constant }\left(\varepsilon_{\mathrm{r}}\right)\end{array}$ & $\begin{array}{l}\text { Coupling } \\
\text { Mechanism }\end{array}$ & $\begin{array}{c}\text { Resonance } \\
\text { Frequency }(\mathrm{GHz})\end{array}$ & $\begin{array}{c}\text { Impedance } \\
\text { Bandwidth (\%) }\end{array}$ & $\begin{array}{l}\text { Peak Gain } \\
\quad(\mathrm{dBi})\end{array}$ \\
\hline [Jamaluddin. M. H et.al.,]/2019 & 10 & $\begin{array}{c}\text { H- shaped } \\
\text { conformal strips }\end{array}$ & 3.85 & 27.7 & 6.8 \\
\hline [Pandey. V. S et.al.,]/2018 & $\begin{array}{c}12.8 \\
66.45\end{array}$ & $\begin{array}{c}\text { Stair shaped slot } \\
2.67\end{array}$ & 5.8 & & \\
\hline [Krishsagar. P et.al.,]/2017 & 4.3 \&t 9.2 & $\begin{array}{c}\text { Conformal } \\
\text { microstrip feed }\end{array}$ & 10 & 131.24 & 10 \\
\hline [Gebril. K. K et.al.,]/2011 & 15 \& 30 & Microstrip line & 5.8 & 12 & 5.1 \\
\hline [Patel. P et.al.,]/2015 & 10.2 & Coaxial probe & 2.82 & 56 & 6.2 \\
\hline [Abdulmajid. A. A et.al.,]/2018 & $3.5 \& 10$ & Cross slots & 11.1 & 21 & 11 \\
\hline [Mongia. R. K et.al.,]/1994 & 100 & Aperture coupling & 7.72 & 3.24 & NA \\
\hline $\begin{array}{l}\text { [Kiran. D. V et.al.]/2020 } \\
{ }^{*} \text { NA- Not available }\end{array}$ & 9.8 & Microstrip line & 6.35 & 23.3 & 5.6 \\
\hline
\end{tabular}

To increase the impedance bandwidth along with miniaturization other techniques are proposed with low dielectric constants. In [Varshney. G et.al.,], the antenna is proposed with metal strips on the sidewalls of the rectangular DRA as shown in fig 7 . The interesting feature of the applied metallic strips in a specified manner is the dual band circular polarization response due to the generation of first and third order degenerate modes. The proposed prototype can be used for satellite communication of $6 / 4 \mathrm{GHz}$ frequency bands.

In [Abedian. M et.al.,], a low-profile rectangular DRA using high permittivity $\left({ }_{\mathrm{er}}=20\right)$ material is proposed. In this geometry, two identical rectangular shaped dielectric layers are joined back to back with microstrip feeding technique inserted in between the two resonators. The lower DRA is embedded within a cut in the substrate to achieve the compactness. Slotted ground plane, open end microstrip feedline fitted in between the two resonators are used for wideband characteristics. Finally, the obtained results are 88.2\% impedance bandwidth with omni directional radiation pattern at $4.8 \mathrm{GHz}$ frequency. Another approach for compact structures is the fractal technique.
In [Kiran. D. V et.al.,], Sierpinski and Minkowski fractals are simultaneously applied for rectangular resonators to reduce the size of the antenna. Along with size reduction, band width can be improved with fractals since with an increase in the fractal iterations one can reduce the quality factor. In this prototype, two rectangular resonators with different dielectric materials are positioned concentrically. Higher permittivity resonator (DR1 with ${ }_{\varepsilon r}=10.2$ ) is embedded inside the lower permittivity material (DR2 with ${ }_{\mathrm{rr}}=4.3$ ) to introduce the dual band operation. The DR1 is undergone with the Sierpinski fractals and the DR2 is undergone with Minkowski fractals with two iteration levels. For each iteration, the bandwidth is improved further and the final impedance bandwidth achieved is 66\% (3.5-7.02 GHz).

\section{DISCUSSION}

From the literature study, it is learned that the rectangular dielectric resonators are best suitable antennas due to its design flexibility compared with other structures. RDRAs can be controlled with two aspect ratios and by properly choosing them, the radiation characteristics can be optimised. For instance, by choosing a high aspect ratio, 
one can design high impedance bandwidth structures by effecting field distribution [Abedian. M et.al,]. RDRA with improper dimensions excites unwanted modes nearer to desired modes causing high cross polarization levels. With an appropriate feeding mechanism, the feed network also acts as a radiator and the geometry works as a hybrid topology for low profile and wide bandwidth applications. Feeding source and location also shows an impact on the excited modes of the antenna. High gain antennas can be realised by making changes in the basic shapes or by exciting higher order modes etc., High permittivity material reduces the antenna size but at the cost of bandwidth.

Recently circularly polarised antennas are drawing more attention because these antennas are independent on transmitter and receiver orientation and having less multipath fading effects due to atmospheric conditions [Kiran. D. V et.al.]. Different techniques are available to alter the radiation characteristics of the resonator and some of reference topologies are listed in Table1.

\section{CONCLUSION}

This article provides an overview of the rectangular dielectric resonator antenna in comparison with the microstrip patch antenna. A brief analysis of resonance modes has been presented including field distributions. Various coupling methods have also been studied. Case studies about wide bandwidth, high gain and size reduction of the rectangular dielectric resonator by various techniques have been discussed. Different models on circular polarization generation have also been listed. Finally, it has been observed that Rectangular DRA with probe coupling is best suitable at lower frequencies and aperture coupling is preferred at higher frequencies, higher order modes correspond to higher resonance frequency and higher antenna gain, circular polarization achieves long range communications.

\section{REFERENCES}

Abdulmajid. A. A., Khalil, Y., \&t Khamas. S. (2018). "Higher-Order-Mode Circularly Polarized Two-Layer Rectangular Dielectric Resonator Antenna”. IEEE Antennas and Wireless Propagation Letters, 17(6), 1114-1117. doi:10.1109/lawp.2018.2834981

Abedian. M., Oraizi. H., Abdul Rahim, S. K., Danesh. S., Ramli, M. R., \&t Jamaluddin, M. H. (2018). “Wideband rectangular dielectric resonator antenna for low-profile applications”. IET Microwaves, Antennas \& Propagation, 12(1), 115-119. doi:10.1049/iet-map.2017.0593

Abedian. M., Rahim, S. K. A., \&t Khalily. M. (2012). "Two-Segments Compact Dielectric Resonator Antenna for UWB Application”. IEEE Antennas and Wireless Propagation Letters, 11, 1533-1536. doi:10.1109/ lawp.2012.2232639

Ankit Kumar Roy., \& Sukla Basu. (2019). "Broadband, High Gain, Narrow Width Rectangular Dielectric Resonator Antenna with Air Gap”. journal of electronic science and technology.doi:10.11989/JEST.1674-

\section{$62 X .70728079$}

Biswajeet Mukherjee, Pragati Patel \&t Jayanta Mukherjee (2020): "A review of the recent advances in dielectric resonator antennas”, Journal of Electromagnetic Waves and Applications, doi: 10.1080/09205071.2020.1744484

Drossos, G., Wu, Z., \& Davis, L. E. (1999). "The air gap effect on a microstrip-coupled cylindrical dielectric resonator antenna”. Microwave and Optical Technology Letters, 20(1), 36-40. doi:10.1002/(sici) 1098-2760.

Fakhte, S., Oraizi, H., \&t Matekovits, L. (2017). “Gain Improvement of Rectangular Dielectric Resonator Antenna by Engraving Grooves on Its Side Walls". IEEE Antennas and Wireless Propagation Letters, 16, 2167-2170. doi:10.1109/lawp.2017.2702584

Gebril, K. K., Rahim, S. K. B. A., \&t Abdulrahman, A. Y. (2011). "Bandwidth Enhancement and Miniaturization of Dielectric Resonator Antenna For 5.8 GHz WLAN". Progress in Electromagnetics Research C, 19, 179-189. doi:10.2528/pierc10121203

Gupta, A., \&t Gangwar, R. K. (2018). “Dual-Band Circularly Polarized Aperture Coupled Rectangular Dielectric Resonator Antenna for Wireless Applications". IEEE Access, 6, 11388-11396. doi:10.1109/ access.2018.2791417

Illahi, U., Iqbal, J., Sulaiman, M. I., Alam, M. M., Su'ud, M. M., \&t Jamaluddin, M. H. (2019). “Singly-Fed Rectangular Dielectric Resonator Antenna with a Wide Circular Polarization Bandwidth and Beamwidth for WiMAX/Satellite Applications”. IEEE Access, 7, 66206-66214. doi:10.1109/access.2019.2917702

Keyrouz, S., \&t Caratelli, D. (2016). “Dielectric Resonator Antennas: Basic Concepts, Design Guidelines, and Recent Developments at Millimeter-Wave Frequencies". International Journal of Antennas and Propagation, 2016, 1-20. doi:10.1155/2016/6075680

Kiran, D. V., Sankaranarayanan, D., \& Mukherjee, B. (2017). "Compact Embedded Dual-Element Rectangular Dielectric Resonator Antenna Combining Sierpinski and Minkowski Fractals". IEEE Transactions on Components, Packaging and Manufacturing Technology, 7(5), 786-791. doi:10.1109/tcpmt.2017.2690463

Kshirsagar, P., Gupta, S., \&t Mukherjee, B. (2017). “A two-segment rectangular dielectric resonator antenna for ultra-wideband application”. Electromagnetics, 38(1), 20-33. doi:10.1080/02726343.2017.1406682

Kumar Mongia, R., \&t Ittipiboon, A. (1997). “Theoretical and experimental investigations on rectangular dielectric resonator antennas". IEEE Transactions on Antennas and Propagation, 45(9), 1348-1356. doi:10.1109/8.623123 Kumari R, Gangwar RK. "Circularly polarized rectangular dielectric resonator antenna fed by a flag shape microstrip line for wideband applications". Microw Opt Technol Lett. 2018;60: 2577-2584. https:// doi.org/10.1002/mop.31402

Luk K.M., Leung K.W.: "Dielectric resonator antennas" (Research Studies Press, Hertfordshire, U.K., 2003) 
Mongia, R. K., \&t Bhartia, P. (1994). "Dielectric resonator antennas-a review and general design relations for resonant frequency and bandwidth". International Journal of Microwave and Millimeter-Wave ComputerAided Engineering, 4(3), 230-247. doi:10.1002/ mmce.4570040304

Mongia, R. K., Ittibipoon, A., \&t Cuhaci, M. (1994). "Low profile dielectric resonator antennas using a very high permittivity material”. Electronics Letters, 30(17), 1362-1363. doi:10.1049/el:19940924

Okaya, A., \&t Barash, L. (1962). "The Dielectric Microwave Resonator". Proceedings of the IRE, 50(10), 2081-2092. doi:10.1109/jrproc.1962.288245

Pan, Y.-M., Leung, K. W., \& Luk, K.-M. (2011). “Design of the Millimeter-wave Rectangular Dielectric Resonator Antenna Using a Higher-Order Mode”. IEEE Transactions on Antennas and Propagation, 59(8), 2780-2788. doi:10.1109/tap.2011.2158962

Pan, Y.-M., Leung, K.-W., \&t Lu, K. (2019). “Study of Resonant Modes in Rectangular Dielectric Resonator Antenna Based on Radar Cross Section”. IEEE Transactions on Antennas and Propagation, 1-1. doi:10.1109/tap.2019.2911198

Pandey, A. K., Chauhan, M., Killamsety, V. K., \&t Mukherjee, B. (2019). "High-gain compact rectangular dielectric resonator antenna using metamaterial as superstrate”. International Journal of RF and Microwave Computer-Aided Engineering. doi:10.1002/ mmce. 21968

Patel, P., Mukherjee, B., \&t Mukherjee, J. (2015). “A Compact Wideband Rectangular Dielectric Resonator Antenna using Perforations and Edge Grounding”. IEEE Antennas and Wireless Propagation Letters, 14, 490-493. doi:10.1109/lawp.2014.2369533

Patel, P., Mukherjee, B., \&t Mukherjee, J. (2016). "Wideband Circularly Polarized Rectangular Dielectric Resonator Antennas Using Square-Shaped Slots”. IEEE Antennas and Wireless Propagation Letters, 15, 1309-1312. doi:10.1109/lawp.2015.2506039

Petosa, A., \&t Ittipiboon, A. (2010). "Dielectric Resonator Antennas: A Historical Review and the Current State of the Art". IEEE Antennas and Propagation Magazine, 52(5), 91-116. doi:10.1109/map.2010.5687510
Petosa, A., \&t Thirakoune, S. (2011). "Rectangular Dielectric Resonator Antennas with Enhanced Gain”. IEEE Transactions on Antennas and Propagation, 59(4), 1385-1389. doi:10.1109/tap.2011.2109690

Petosa, A., Ittipiboon, A., \&t Thirakoune, S. (2002). "Perforated dielectric resonator antennas". Electronics Letters, 38(24), 1493. doi:10.1049/el:20021074

Petosa. A et.al., "Dielectric Resonator Antenna Handbook”. Norwood, MA, USA: Artech House, 2007

Ranjbar Nikkhah, M., Rashed-Mohassel, J., \& Kishk, A. A. (2013). "High-Gain Aperture Coupled Rectangular Dielectric Resonator Antenna Array Using Parasitic Elements". IEEE Transactions on Antennas and Propagation, 61(7), 3905-3908. doi:10.1109/ tap.2013.2254451

S. H. H. Mashhadi, Yong-Chang Jiao \& Jingdong Chen (2020): "Wide 3-dB beamwidth step-walled rectangular dielectric resonator antenna”, Journal of Electromagnetic Waves and Applications, DOI: 10.1080/09205071.2020.1713224

Varshney G, Pandey VS, Yaduvanshi RS (2018). “Axial ratio bandwidth enhancement of a circularly polarized rectangular dielectric resonator antenna”. International Journal of Microwave and Wireless Technologies 1-7. https://doi.org/10.1017/ S1759078718000764

Varshney, G., Gotra, S., Pandey, V., \& Yaduvanshi, D. R. (2019). "Dual-Band Circular Polarization Generation Technique with the Miniaturization of a Rectangular Dielectric Resonator Antenna”. IET Microwaves, Antennas \& Propagation. doi:10.1049/ iet-map.2019.0030

Yaduvanshi, R. S., \&t Parthasarathy, H. (2016). "Rectangular Dielectric Resonator Antennas". doi:10.1007/978-81-322-2500-3

Yuan Gao, Ooi, B.-L., Wei-Bin Ewe, \& Popov, A. P. (2006). "A compact wideband hybrid dielectric resonator antenna”. IEEE Microwave and Wireless Components Letters, 16(4), 227-229. doi:10.1109/ lmwc.2006.872101

Zou, M., \& Pan, J. (2016). Wide Dual-Band Circularly Polarized Stacked Rectangular Dielectric Resonator Antenna. IEEE Antennas and Wireless Propagation Letters, 15, 1140-1143. doi:10.1109/lawp.2015.2496361 